An analysis of available data on diet shows little group variation in the consumption of fats and oils between populations of urban and rural areas and between income groups in the United States.

\title{
Fat Consumption in the United States
}

\section{FREDERICK H. EPSTEIN, M.D.}

$\mathrm{V}$ ITAL STATISTICS show wide variation in arteriosclerotic heart disease mortality among different States of the Union (1). Such variations, if real, might be related to differences in dietary habits, particularly with regard to fat consumption. The U.S. Department of Agriculture has published extensive tables on food consumption based on household interviews conducted in the spring of 1955 , which permitted testing for differences among the four major regions of the Union (North East, North Central, South, and West), between urban and rural areas, and between income groups (2). Variations in the quantity or types of food consumed among the population segments thus defined would be of help in identifying groups suitable for more detailed epidemiological studies of the relation between nutrition and cardiovascular disease.

This analysis of the U.S. Department of Agriculture data searches for such variations. It was realized, however, that the original survey was intended to serve a quite different purpose, that is, to collect information "for administration of public programs affecting food supply, distribution and consumption; for educational programs to improve food habits, and for private efforts to broaden and improve the

Dr. Epstein is associate professor of epidemiology, School of Public Health, University of Michigan. This study was supported by a grant from the $\mathrm{Na}$ tional Heart Institute, Public Health Service. marketing of foods" (2,3). Data collected for one purpose do not necessarily lend themselves to analysis for another. Yet this study seemed justified in view of the paucity of detailed information on the food habits of subgroups of the general population in the United States and their possible relation to disease patterns, particularly atherosclerosis.

Several publications of the U.S. Department of Agriculture have summarized part of the information culled for the survey (4-7). In particular, the average fat consumption in the four major regions, North East, North Central, West, and South, was analyzed in terms of saturated and unsaturated fatty acid content but no breakdowns by degree of urbanization and income were made $(5,7)$. Our data present a systematic and simultaneous analysis of almost all relevant fat-containing food items in the diet by region, by degree of urbanization, and by income group. Moreover, the data given in the tables published by the U.S. Department of Agriculture refer to average household rather than per capita consumption, regardless of the fact that certain food items are eaten only by a proportion of the population. In this analysis, data are presented for per capita consumption among users only.

Our findings suggest that major overall dietary habits of fat consumption vary remarkably little among different broad segments of the general population within the United States, a significant observation from the point of view 
of epidemiological research into the causes of atherosclerotic diseases.

\section{Methods of Analysis}

The tables on "Dietary Levels of Households" were used for the determination of total calorie, fat, and protein consumption (3). Individual food items were analyzed, using the tables on "Food Consumption of Households" (2). These tables provide data on average consumption in households and also the average number of persons per household in different regions and groups. Thus by dividing household consumption by household size, per capita food consumption of the total segment of the population under consideration may be calculated.

A further correction is required for calculating consumption among those actually using the food item in question. This can be accomplished by dividing the average per capita consumption by the percentage of "users," a figure also given in the tables. An error may be introduced by this method since it tacitly assumes that household size is the same among users and non-users, not necessarily a correct assumption. Thus, in Great Britain at least, it has been shown that the number of children in a family, a decisive factor in household size, is more critical than social status in determining food habits (8). In defense of using the correction in question, it may be said that the average household size in the four different areas of comparable urban and rural localities is generally so similar ( 3 to 4 persons per household) that the assumption of comparable household size among users and non-users may produce no more or possibly even less error than the uncertainties inherent in gathering the basic dietary information, or the inevitable failure to adjust for the varying ages among the household members.

The basic data refer to food consumed rather than food purchased. Nevertheless, there is likely to be some overestimate of intake because of "food waste," a quantity notoriously difficult to gauge. Uncertainty regarding food waste is particularly troublesome in estimating fat intake.

Eighty-eight charts have been prepared. Twelve of these depict the intake of calories, protein, and fat in the four major regions. The remaining 76 charts pertain to household and per capita consumption of 19 different fat-containing food items. Each chart represents one of the four regions. Each of the 88 charts includes breakdowns into the three degrees of urbanization, urban, rural nonfarm, and rural, and, within these, different income groups.

\section{Calories, Protein, and Fat}

The large number of charts precluded publication in their entirety. Instead, a summary of each set of charts is presented, including some representative diagrams for illustration (figs. 1 and 2). Brief, descriptive annotations of the charts are obtainable from the author upon request.

Average total caloric intake tends to be somewhat lower in the urban and rural nonfarm areas of the North East than in the comparable areas of the three other main regions of the country. There is a general tendency for caloric intake to increase, moving from town to country; intake in the farm areas is uniformly highest, including the North East. There is no discernible association between caloric intake and income level, except for a slight positive correlation in the urban North East and in the urban and rural nonfarm areas of the South and West.

Average protein intake seems to be no different by region or area, except for a somewhat lower intake in urban and rural nonfarm areas of the South. In the same areas in the South and the West, the protein intake tends to rise with income; a less definite but suggestive correlation with income is noted in the two urban areas of the North.

The trends for total fat and protein consumption are similar except that farm consumption usually tends to be higher than urban and rural nonfarm consumption (fig. 1). As in the case of protein, fat intake tends to rise with income in the urban and rural nonfarm areas in the South and West, income group 1 denoting the lowest and income group 8 the highest level. It is difficult to decide from inspection of the graphs whether any of the less obvious differences between income groups are significant statistically or nutritionally, taking into account 
Figure 1. Total fat consumption in four regions of the United States
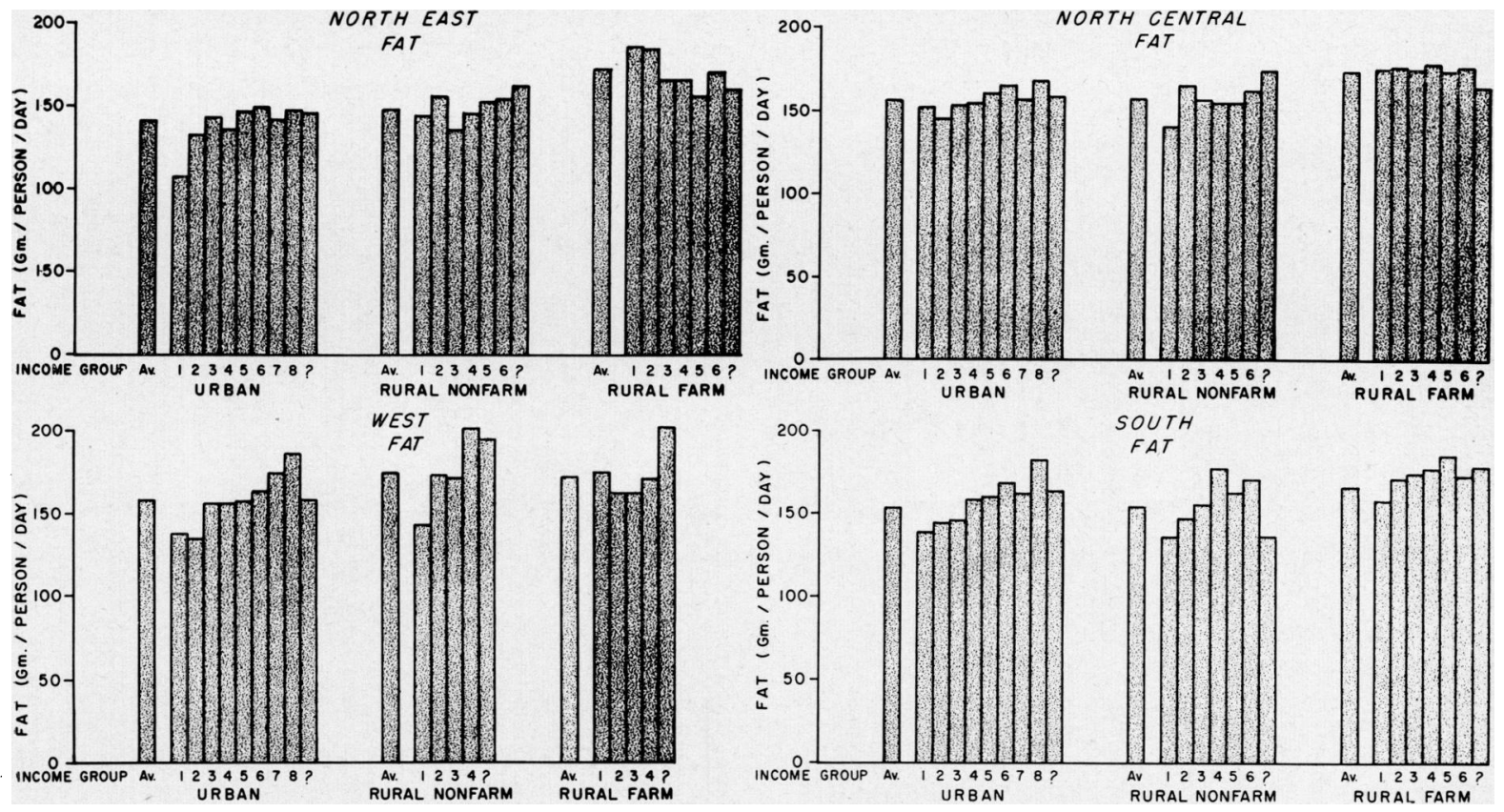

ANNUAL INCOME. In urban areas: Group 1, under $\$ 2,000$. Group $2, \$ 2,000-2,999$. Group 3, $\$ 3,000-3,999$. Group 4, $\$ 4,000-4,999$. Group 5, $\$ 5,000-5,999$. Group 6, $\$ 6,000-7,999$. Group 7, $\$ 8,000-9,999$. Group $8, \$ 10,000$ and over. In rural areas, except in the West: Same as

the variations inherent in the method of data collection.

In summary, there is a considerable degree of uniformity in average caloric, protein, and fat intake, irrespective of region (North East, North Central, South, or West) or area (urban, rural nonfarm, and farm). However, caloric intake tends to be lower in the two more urban areas in the North East, and there is a distinct tendency for all three variants to show a positive correlation with income in the two more urban areas in the South and West and possibly in the other two regions as well.

\section{Fats and Oils}

The "total fats and oils" category includes butter, margarine, shortenings, salad dressings, and salad and cooking oils. Household fat consumption increases with diminishing degrees of urbanization in all four regions (fig. 2). This trend, as well as the higher consumption in the South, reflects household size.

in urban areas except for group 6 which refers to incomes of $\$ 6,000$ and over. In rural areas in the West: Group 1, under $\$ 2,000$. Group 2, $\$ 2,000-3,999$. Group 3, $\$ 4,000-5,999$. Group 4, $\$ 6,000$ and over. Incomes not classified denoted by question mark.

Since differences in average household consumption tend to reflect differences in household size rather than true differences in consumption between groups, only per capita consumption will be discussed. Household data may be obtained from the detailed tabulations. Per capita consumption of fats and oils is strikingly similar in all regions and within comparable areas and income groups, except for a somewhat lower level in the urban North East, where total caloric and total fat consumption are also lower. In each region, except in the West, consumption per person is lowest in the urban and highest in the rural areas.

Baked products, not being primarily fat-containing, have been excluded from this analysis. While the consumption of baked products and prepared foods is known to be higher in urban than rural areas $(6)$, it is unlikely that their inclusion would have materially altered the general picture of fat consumption. Baked goods form but a part of the category of "grain products," a group which, even as a whole, accounts 
Figure 2. Separated fat and oil consumption in four regions of the United States

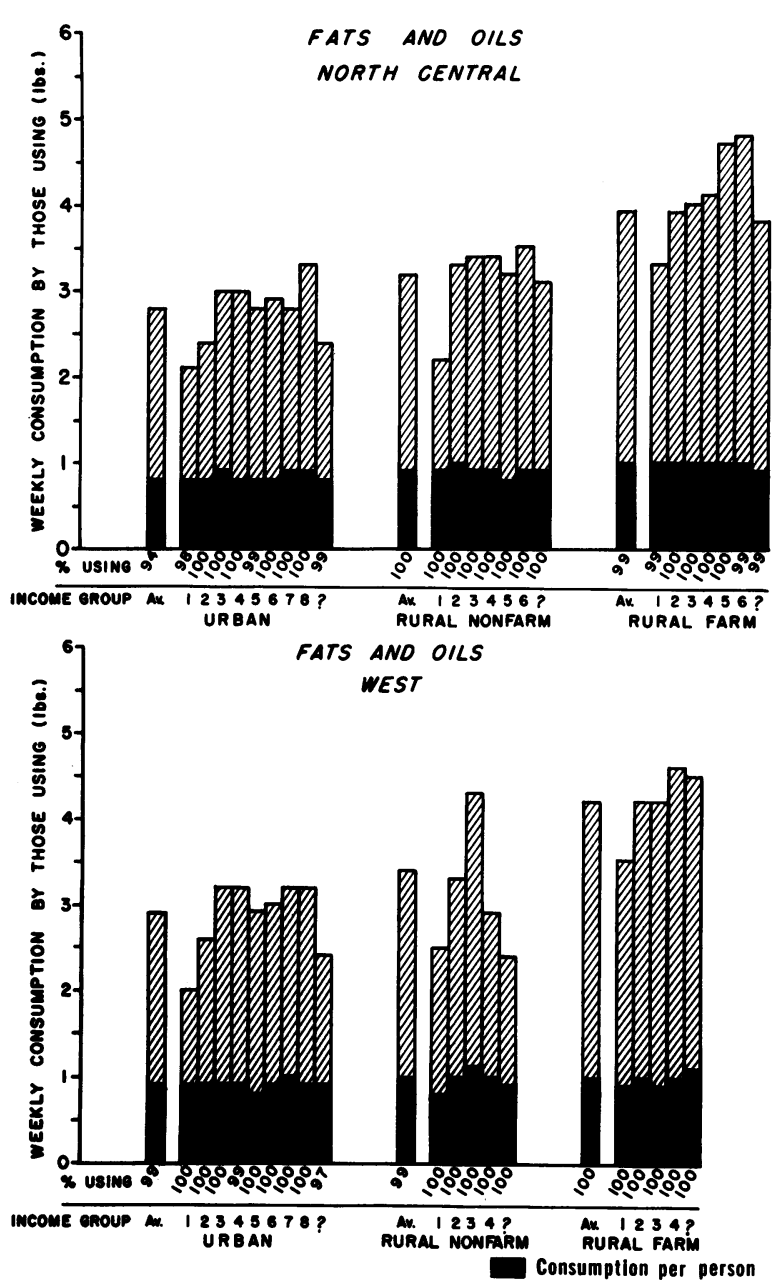

Note: For annual income of the groups see figure 1.
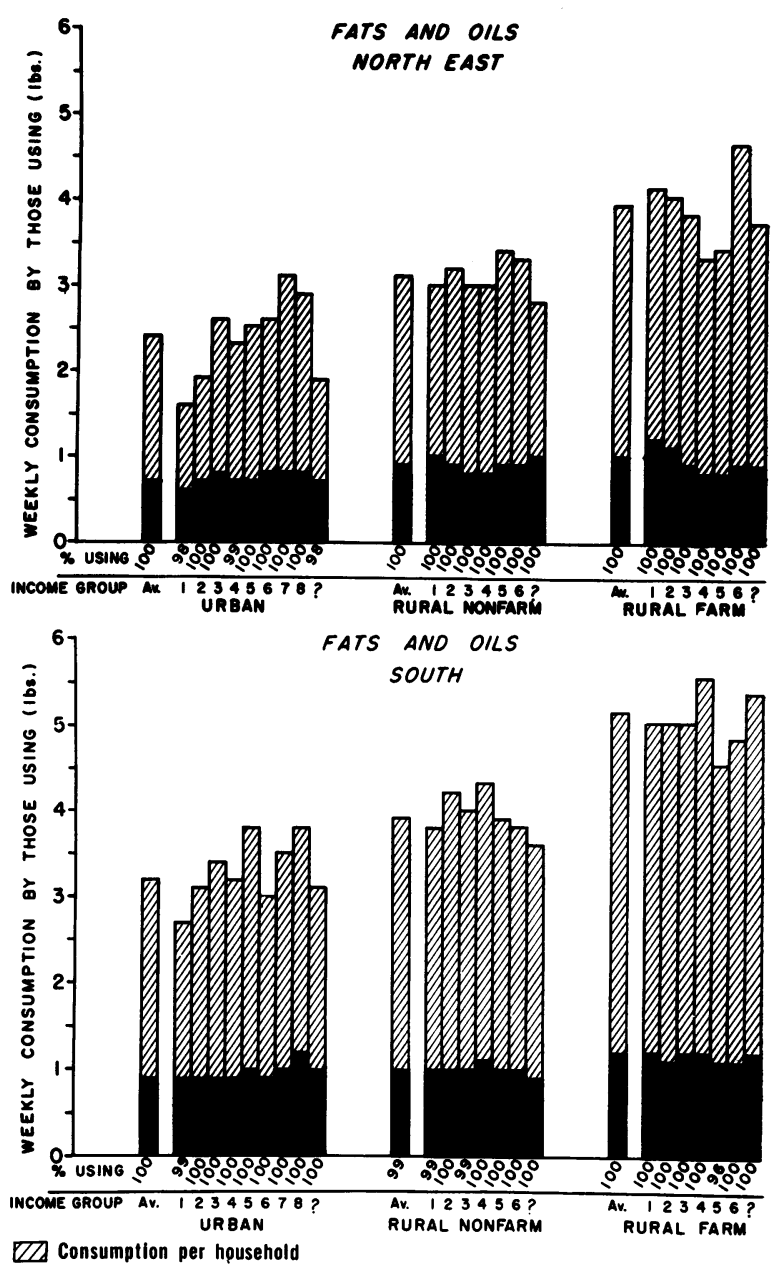

for no more than 5 to 7 percent of the calories derived from fat in the different regions and areas (3). It is not implied that baked products are an unimportant source of fat or calories for some people or groups.

It is clear that the total consumption of separated fats is high, regardless of region, degree of urbanization, and income. The types of separated fats contributing to this total picture might be suspected to differ appreciably among the various population groups, but further analysis gives little support to this hypothesis. When the consumption levels of butter, margarine, shortenings (lard and nonlard), salad dressings, and salad and cooking oils are charted individually, no striking differences among regions, areas, or income levels emerge. More-

over, since the proportion of users of these various types of separated fats is reasonably similar from one region, area, or income level to the next, these observations rule out major intergroup differences in the food patterns under discussion. Yet some differences must exist since we must assume that the non-users of one particular type of fat substitute another, for example, vegetable shortening for lard, if we are to account for the similarity in total fat and oil consumption among different subgroups. The basic tabulations do not provide the breakdowns necessary for such an analysis, which was beyond the scope of the original purposes of the survey as explained. Nevertheless, significant group variations in this regard may well exist. Thus, although relatively few households use 
Salad and cooking oils, consumption tends to be high among those who do, presumably at the expense of the more saturated forms of fat.

\section{Dairy Products}

Detailed tabulations have been made for milk (fresh fluid and evaporated), cream, ice cream and ice milk, cheese, and eggs. In general, the findings are similiar to those for separated fats. Little variation in consumption level has been encountered among the users in the different regions, areas, and income groups. Likewise, for each given dairy product, the percentage of users tends to be comparable from one population subgroup to the next. Rural areas in general and the South are exceptions. Consumption is higher in farm districts and lower in the southern States. Within the dairy products group, there is less room for substitutions than in the "fats and oils" category and there is even firmer ground for stating that there are no major intergroup differences in consumption.

\section{Meat, Poultry, and Fish}

As in the case of fats and oils and dairy products, the economic leveling process has tended to equalize differences in meat, poultry, and fish consumption. Exceptions are a lower meat consumption in the South, at all degrees of urbanization, and a slight positive association between meat consumption and income. Also, the proportion of households using fish is higher in the North East. The present findings are not in accord with the statement that meat is of lesser importance in rüral diets (5). The data in support of this claim are based on the total category of "meat, poultry, and fish" and, not being expressed as per capita consumption of users, can be explained by the fact that the proportion of users of poultry and fish is higher in urban than rural areas.

\section{Comments and Recommendations}

It would seem permissible to conclude from these data that selected income groups in certain regions and areas of the United States do not appear to offer themselves as units for more detailed study of the relationship between fat intake and coronary heart disease. Yet, it is likely that there are more narrowly defined cultural and religious subgroups within the United States differing sufficiently in dietary habits to permit a study of the relationships between diet and disease in this country which might be more easily interpreted than certain international comparisions.

There is also a need for concurrent clinical and dietary studies among populations or representative population samples, using methods of dietary history taking of adequate validity and reliability, in order to delineate differences in dietary habits between individuals within the same group rather than searching for differences between groups. In this light, the original interview records collected in the survey by the U.S. Department of Agriculture may still offer opportunity for more detailed scrutiny.

Originally it was hoped that information on the type and amount of fat-containing foodstuffs would provide an indirect measure of the degree of saturation of fats in the diet of a given group. It seemed too difficult, however, to gain a consistent picture of dietary fatty acids content by reconstructing the contributions of individual food items. Stiebeling has analyzed the survey data on fats in terms of saturated, oleic, and linoleic acid content in the four regions but provided no further breakdown by degree of urbanization or income, nor did she correct for the effect of non-usage $(y)$. This analysis suggested a somewhat higher ratio of unsaturated to saturated fatty acid in the South; the other three regions showed no appreciable dissimilarities in this regard.

It is not possible to extrapolate these findings to the more detailed ramifications of the populations into the areas and income groups discussed here. If the general conclusion is correct that no major differences in the consumption of fat-containing foods exist between the population segments considered, the same conclusion would generally apply to the constituent fatty acids.

\section{Summary}

An analysis, based on the household food consumption survey made by the U.S. Depart- 
ment of Agriculture in the spring of 1955, of the consumption of calories, protein, and fat, and the major fat-containing foods, has been made. The consumption of "fats and oils," "dairy products," and "meat and fish" has been broken down into 19 different food items. For each of these, data are presented on the proportion of users of the various foods, their consumption level among the households using them, and the per capita consumption by the users. These data are further broken down by the four major regions of the United States, degree of urbanization, and income level. This report, differing in aim from others published, is based on calculations including only households actually using the food item rather than averages for the total group regardless of the proportion of users.

Epidemiological studies into the relationship between fat intake and atherosclerosis aim at delineating population segments differing in fat intake. The present analysis was undertaken in the hope that the extensive and detailed fragmentation of the total population by region, area, income, and proportion of users might identify subgroups exposed to possible preferential risk by a high intake of certain fats. Allowing for methodological difficulties, no such susceptible population subgroups could be shown to exist in the United States in terms of the particular breakdowns made. The feasibility of epidemiological studies of the kind envisaged within the United States would seem to depend, therefore, on identifying intragroup differences between individual members of the community rather than intergroup differences between broadly defined regional or socioeconomic population segments.

\section{DOCUMENTATION NOTE}

The complete set of 88 charts and the tables from which the charts were drawn, covering variations in the fat and oil consumption among the population segments defined by the U.S. Department of Agriculture survey of diet in the United States by household interview, have been deposited as document No. 6142 with the American Documentation Institute Auxiliary Publications Project, Photoduplication Service, Library of Congress, Washington 25, D.C. A photoprint may be obtained by remitting $\$ 25$; a $35-\mathrm{mm}$. microfilm copy by remitting $\$ 7$. Cite document number. Advance payment is required. Make checks or money orders payable to Chief, Photoduplication Service, Library of Congress.

\section{REFERENCES}

(1) Enterline, P. E., and Stewart, W. H. : Geographic patterns in deaths from coronary heart disease. Pub. Health Rep. 71: 849-855, September 1956.

(2) U.S. Department of Agriculture: Food consumption of households in the Northeast, Report No. 2; North Central region, Report No. 3; South, Report No. 4 ; and West, Report No. 5. Household Food Consumption Survey, 1955. Washington, D.C., U.S. Government Printing Office.

(3) U.S. Department of Agriculture: Dietary levels of households in the Northeast, Report No. 7; North Central region, Report No. 8; South, Report No. 9 ; and West, Report No. 10. Household Food Consumption Survey, 1955. Washington, D.C., U.S. Government Printing Office.

(4) Clark, F. : Family diets today. Talk presented at Nutrition Education Conference, Washington, D.C., April 1, 1957.

(5) U.S. Department of Agriculture: Food consumption and dietary levels of households in the United States. Agriculture Research Service Pub. No. 62-6. Washington, D.C., U.S. Government Printing Office, August 1957.

(6) U.S. Department of Agriculture: Household use of fats and oils in the United States. National Food Situation Pub. No. 82. Washington, D.C., U.S. Government Printing Office, October 1957.

(y) Stiebeling, H. K. : Food and nutrition consumption trends and consumer problems. Fed. Proc. 17 : 770-774, July 1958.

(8) Wright, N. C.. : The changing feeding habits of the Nation. Roy. Soc. Health J. 78: 256-269, MayJune 1958. 